\title{
INVESTIGATING ALOFT AEROSOLS OVER CENTRAL-EASTERN CHINA USING CALIPSO MEASUREMENTS
}

\author{
Jiaheng Zou ${ }^{1}$, Kai Qin ${ }^{1} *$, Jian $\mathrm{Xu}^{2}, \mathrm{Xu} \mathrm{Han}^{1}$
}

\author{
${ }^{1}$ School of Environment Science and Spatial Informatics, China University of Mining and Technology, Xuzhou 221116, China - \\ zoujiaheng@cumt.edu.cn, qinkai20071014@163.com \\ ${ }^{2}$ German Aerospace Center, Remote Sensing Technology Institute, Weßling, Germany - jian.xu@dlr.de
}

Commission III, WG III/8

KEY WORDS: Haze, Aloft aerosol, Central-eastern China, Optical property, CALIPSO

\begin{abstract}
:
The rapid development of China in the last decade has brought about serious environmental problems, among which the air quality has attracted much attention. Especially in the winter, haze events with PM2.5 as the primary pollutant frequently occur, which has a huge strike on people's health. Such cumulative anthropogenic aerosols at surface over haze pollution regions could be lifted upwards by vertical turbulent mixing forming elevated haze layers that subsequent transport to distant regions. This paper attempts to analyze layer top altitude, ratio of anthropogenic source and optical properties by counting events occurring in aloft aerosols layer. CALIPSO satellite instruments are used for statistical analysis by screening layer data over central-eastern China from 2007 to 2016 . In the most economically active and polluted areas of China, the North China Plain (NCP) and the Yangtze River Delta (YRD) are compared to analyze trend variations over ten years. Results shows that the frequency of occurrence of aloft layer in South China are higher than in North China, indicating that heat has a strong lifting effect on the planetary boundary layer (PBL). Further, the NCP has a unique high frequency value at $2.5 \mathrm{~km}$, while the YRD has two peaks, $3.5 \mathrm{~km}$ and $2 \mathrm{~km}$ respectively. Moreover, in the past five years in the NCP (2011-2016) and YRD (2012-2016) regions, the anthropogenic source of pollutants dominated by smoke showed a downward trend year by year. In addition, monthly proportion of smoke and polluted dust are analyzed in NCP and YRD winter. Finally, the volume depolarization ratio is almost distributed within 0.2, indicating that the shape of the particles is irregular. The particulate color ratio has a sharp peak near 0.4-0.7 suggesting that smaller particles dominate the size distribution during the winter months.
\end{abstract}

\section{INTRODUCTION}

The rapid industrialization and urbanization have led to serious air pollution problems in China. In January 2013, a heavy haze with record-breaking PM2.5 (particulate matter with diameters smaller than $2.5 \mu \mathrm{m}$ in aero-dynamics) level shrouded most parts of central-eastern China, which has attracted a lot of attention over the world [Bi et al., 2014; Sun et al., 2014; Tao et al., 2014]. Thereafter, in winter season, persistent regional haze pollution frequently occurred in central-eastern China because of stable synoptic conditions with weak surface wind and vertical temperature inversion that are unfavorable for pollutant dispersion [Zheng et al., 2015;Tao et al., 2016; Sun et al., 2016]. The fine particles (i.e., PM2.5) causing the Chinese winter haze pollution are mostly derived from anthropogenic emissions including those from industries, vehicles, and secondary aerosol formation from precursors (NOx, SO2, NH3, and VOCs) [Huang et al., 2014]. Such cumulative anthropogenic aerosols at surface over haze pollution regions could be lifted upwards by vertical turbulent mixing forming elevated haze layers that subsequent transport to distant regions. Yang et al., [2012] revealed that the regional haze in winter formed in the North China Plain can be transported to Northeast China in $\sim 1-3$ days. Qin et al., [2016] reported a regional transport of a winter haze episode in China using ground-based Lidar measurements and CALIPSO (CloudAerosol Lidar and Infrared Pathfinder Satellite Observations) satellite images.

Given that aerosol properties may vary significantly as a function of height, knowledge of aloft aerosol layers is important to study the regional transport and climate radiative forcing [Guo et al., 2016]. Moreover, aloft aerosol layers are critical to satellite remote sensing of air quality, e.g. using satellite retrieval of column AOD (Aerosol Optical Depth) to evaluate the surface PM2.5 concentration, because they can make a substantial contribution to the total AOD. Niranjan et al., [2007] reported certain high altitude aerosol layers during the months of March/April 2005, 2006 at Visakhapatnam, east coast of peninsular India observed by a micro pulse Lidar. Salinas et al., [2013] investigated the physical and optical properties of the trans-boundary biomass burning smoke over Singapore by analyzing AERONET Sunphotometer and MPLNET MPL (Micro Pulse Lidar) measurements. Cottle et al., [2014] observed multiple wildfires smoke layers reaching western Canada from Boreal Asia by Lidar measurements that led to a substantial increase in particulate concentrations near the surface. Kar et al., [2015] detected strong pollutant outflows from Mexico City metropolitan area during winter using CALIPSO lidar measurements, which often flowed as far north as the Texas coast. Han et al., [2015] evaluated the impacts of aloft aerosol-plume and aerosol-type on the correlation of AOD-PM. During the TCAP (Two-Column Aerosol Project) from June 2012 to June 2013, Berg et al., [2016] found aloft aerosol layers in both the Cape Cod and maritime columns using a high-spectral resolution Lidar, which contributed up to $60 \%$ of the total AOD. Sarangi et al., [2016] observed persistent elevated aerosol layers during monsoon onset period over Kanpur and found their radiative effect increases the stability of the lower troposphere.

To our best knowledge, there has been little research focused on the aloft anthropogenic hazes in China. The objective of this study is to provide a foundation for assessing the impacts of Chinese aloft anthropogenic haze layers on aerosol transport and climate radiative effect by investigating their frequency of occurrence, altitudes, thickness, and optical properties. In order

\footnotetext{
* Corresponding author
} 
to depict primarily the anthropogenic haze influence, our study focuses on the winter months, when the biomass burning influences are at their minimum. In winter the cloud occurrences are also expected to be lower than those in summer, offering more clear sky aerosol observations. This paper is organized as follows: Section 2 shows data sets. Section 3 describes data screening methods. Section 4 provides a long-term analysis of 10 years CALIPSO aloft aerosol layer features over central-eastern China.

\section{DATA SETS}

The CALIPSO launched in 2006 is a member of the A-Train constellation of satellites. CALIOP (Cloud-Aerosol lidar with Orthogonal Polarization) loaded on CALIPSO a dual-wavelength (532 and $1064 \mathrm{~nm}$ ) elastic backscatter Lidar with the capability of polarization-sensitive observations at $532 \mathrm{~nm}$ [Winker et al., 2007]. The CALIPSO Level-1 products are the attenuated backscatter profiles, polarized parallel and perpendicular to the transmitted laser pulses at $532 \mathrm{~nm}$ and the total attenuated backscatter profiles (i.e., parallel and perpendicular components combined) at $1064 \mathrm{~nm}$. The aerosol backscatter and extinction coefficients computed based on the CALIPSO Lidar ratio selection algorithm [Omar et al., 2009], have been evaluated by airborne and ground-based Lidar and AERONET Sunphotometer measurements [Rogers et al., 2009; Wu et al., 2014].

In this study, we used 10 years (2007-2016) Level-2 Aerosol Layer products in December, January and February from versions 3.01 (1 January 2007 to 28 February 2011), 3.02 (1 December 2011 to 28 February 2013), 3.30 (1 December 2013 to 28 February 2016) and 3.40 (1 to 31 December 2016) of the CALIPSO data. With respect to earlier releases, this version provides significant improvements in the areas of aerosol layer detection, boundary layer cloud clearing and cloud-aerosol discrimination. The Level-2 Aerosol Layer data identifies the top and base heights of each aerosol at a 5-km horizontal resolution, along with the layer optical depth, and aerosol type by the use of a number of complex algorithms from the Level-1 data [Winker et al., 2007; Liu et al., 2009]. In each profile, a maximum of the layer number 8 is populated in the aerosol layer products. These aerosol layers are classified into six subtypes (i.e., clean marine, dust, polluted continental, clean continental, polluted dust and smoke), among which "smoke" represents aerosols from biomass burning while polluted dust represents a mixture of "dust" and "smoke" [Omar et al., 2009]. They have been assessed by compared with corresponding aerosol types derived from AERONET data [Mielonen et al., 2009] and from airborne highspectral resolution Lidar measurements [Burton et al., 2013] with overall good agreement.

\section{DETERMINING ALOFT ANTHROPOGENIC AEROSOLS USING CALIPSO MEASUREMENTS}

The data were filtered using two criteria to ensure retrievals' quality. First, only cloud-free profiles were used. The CALIPSO cloud and aerosol detection (CAD) score provides a numerical confidence level for the classification of layers by the CALIOP cloud-aerosol discrimination algorithm. It was a requirement that the CAD score is less than -80 (i.e., high confidence aerosol layers). Second, the Extinction Quality Control (QC) flag were also considered, which is reported for each layer for which extinction retrieval was attempted. Only those data for which the initial lidar ratio is unchanged (extinction $\mathrm{QC}=0$ ) or for which extinction profile is solved using constrained retrieval algorithms (extinction QC = 1) or where the aerosol layer is totally attenuating (extinction $\mathrm{QC}=16$ ). The study domain of centraleastern China was selected as a bounded region by $26^{\circ} \mathrm{N}-42^{\circ} \mathrm{N}$ and $112^{\circ} \mathrm{E}-123^{\circ} \mathrm{E}$, including the regions of North China Plain
(NCP) and Yangtze River Delta (YRD) that takes the lead in suffering from air pollution. After the data filtering, total 249,089 profiles remained for the 10 years data. As shown in Figure 1, the red lines represent the ground coordinates of these profiles for the daytime overpasses of CALIPSO (in ascending mode), whereas the blue lines indicate those for nighttime overpasses of CALIPSO (in descending mode).

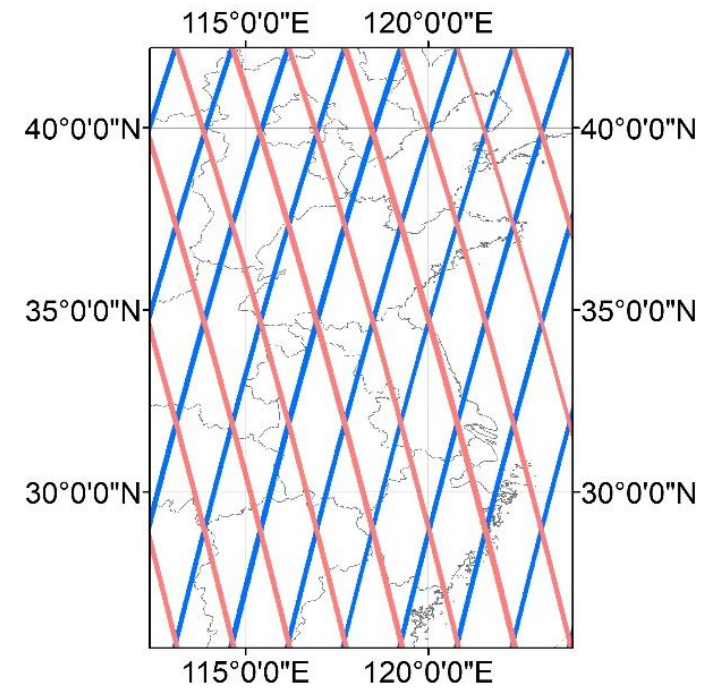

Figure 1. Satellite orbital distribution in the study area (red=daytime, blue=nighttime)

Following the method proposed in Berg et al. [2016], aloft aerosol layers can be determined by comparing the aerosol layer top and thickness. Specifically, an aerosol layer is classified as being a layer aloft when its thickness is less than two thirds of the height of the top of the layer and larger than $300 \mathrm{~m}$. Furthermore, as in previous reports [Tao et al., 2014; Zhang et al., 2015; Qin et al., 2016;], the Chinese anthropogenic haze layers are usually recognized as "smoke" or "polluted dust" in CALIPSO, only layers with these two subtypes were accepted here. Since the detecting sensitivity of CALIPSO to the aerosol extinction is 0.02 $\mathrm{km}-1$, the aloft aerosol layer optical depth is greater than 0.02 times the corresponding layer thickness. In addition, the uncertainty of optical depth should be suppressed, therefore the optical depth uncertainty derived from Level-2 layer scientific dataset is less than 99.9 [Kar et al., 2015]. Aloft aerosol layer data quality control and determination methods are listed in Table 1.

Table 1. Aloft aerosol layer data quality control and determination methods

\begin{tabular}{ll}
\hline Parameters & Value \\
\hline Extinction QC_532 & $0,1,16$ \\
CAD score & $-100 \leq \mathrm{CAD} \leq-80$ \\
Layer top/base altitude & (top-base) $<2 / 3 *$ top; (top- \\
Optical depth & base) $\geqslant 300 \mathrm{~m}$ \\
& Optical depth $\geqslant 0.02 *$ layer \\
& thickness \\
Optical depth uncertainty & Optical depth uncertainty $<$ \\
& 99.9 \\
\hline
\end{tabular}

Since the identification of the aloft aerosol layer uses only the single profile layer data, the spatial and temporal continuity of the aerosol is not considered lead to some areas being misclassified as aloft layer due to being too sensitive for stratified data. To prevent the above situations and obtain continuous aloft aerosol layer, Level-1B total attenuation backscatter data and Level-2 VFM vertical feature mask data are introduced as verification data, which can take the correlation of aerosol 
distribution into account before and after satellite transit to ensure the continuity of the aloft aerosol layer. By combined analyzing the images of $532 \mathrm{~nm}$ total attenuated backscatter, vertical feature mask and aerosol subtype, aerosol layers aloft can be identified. During the investigated time period, total 330 CALIPSO orbits occurred over eastern China among which we found 107 altitude plumes likely due to anthropogenic hazy aerosol. In the Level-1B and VFM data, it is possible to visually interpret whether there is obvious delamination and to obtain the layer top altitude of the aloft aerosol. Thus, the recognition result of aloft aerosol layer can be compared with the verification data to obtain better recognition results. In this paper, we select 9 different satellite orbits, which are divided into 36 blocks according to the latitudes and longitudes. The sub-satellite trajectory of each block covers about $220 \mathrm{~km}$, corresponding to about 45 vertical profiles (resolution $5 \mathrm{~km}$ ). The ratio of the identified profiles to the total number of profiles in the blocks is used as a determination index. The ratio compared with the Level-1B or VFM data were classified into two groups, the aloft layer group and un-aloft layer group. The statistics results are shown in Table 2. There are 21 aloft layers and 15 un-aloft layers in the two groups, respectively. The lower quartile of the aloft group is 0.69 , and the upper quartile of the un-aloft group is 0.56 , indicating that the ratio of the identified profile of each block to the total profiles in the aloft layer classified by visual interpretation should be more than 0.56 , in order to meet the continuous distribution of aerosol in time and space. Therefore, at the end of the detection and recognition algorithm, the track area to be identified is divided into the same intervals (45 vertical profiles) with a ratio of the identified profiles to the total profiles. If the ratio is greater than 0.56 , it will be considered as aloft aerosol, and if not, it is not considered to be.

Table 2. Statistics of the ratio of the identified profiles to the total number of profiles

\begin{tabular}{lllllll}
\hline ratio & $\begin{array}{l}\text { co } \\
\text { unt }\end{array}$ & mean & $\max$ & min & $\begin{array}{l}\text { upper } \\
\text { quartile }\end{array}$ & $\begin{array}{l}\text { lower } \\
\text { quartile }\end{array}$ \\
\hline
\end{tabular}

\begin{tabular}{lllllll}
\hline Aloft & 21 & 0.7381 & 1.00 & 0.35 & 0.89 & 0.69 \\
Un-aloft & 15 & 0.4687 & 0.64 & 0.31 & 0.56 & 0.36 \\
\hline
\end{tabular}

\section{STATISTICAL ANALYSIS OF ALTITUDE, AEROSOL SUBTYPE AND OPTICAL PROPERTIES FOR AEROSOL ALOFT LAYER}

Figure 1 shows the occurrence frequency of the aloft aerosol layer with a resolution of $0.25^{\circ}$ in the four seasons of spring(MAM), summer(JJA), autumn(SON) and winter(DJF). In general, the aloft layer of South China appears more frequently than that in the North China due to the heating effect of solar radiation on aerosol. Yet in the summer, the frequency of occurrence in the north is higher than that in the south, indicating that dry heat is more conducive to lifting the aerosol layer than damp heat. Polluted dust is likely a mixture of dust and smoke in the free troposphere. Nearly all of the aerosol layer tops observed between 1.5 and $5 \mathrm{~km}$ are associated with layers aloft during July. Most episodes occur mainly from March to September, with higher altitude in spring and lower in summer, making the summer months most susceptible to smoke intrusions into the PBL.

Further, we statistically analyzed the aloft layer altitude frequency of the central-eastern China(Figure 2a), the North China Plain(NCP, Figure 2b) and the Yangtze River Delta(YRD, Figure 2c). The aloft layer altitude of central-eastern China is a unimodal structure with a maximum frequency in $2-3 \mathrm{~km}$ and a ratio of more than $64 \%$ in $1-3.5 \mathrm{~km}$. The aloft layer altitude of $\mathrm{NCP}$ is also a unimodal structure, but it is steeper than that in the eastern China with an extreme frequency value range from $1.5 \mathrm{~km}$ to $2 \mathrm{~km}$. The distribution of the aerosol layer altitude for layers aloft in Figure 2c is bimodal in the YRD. The data shows one peak near $3.5 \mathrm{~km}$ and a second peak near $2 \mathrm{~km}$ with a significant number of aerosol layer tops between $1 \mathrm{~km}$ and $4 \mathrm{~km}$ above the surface.

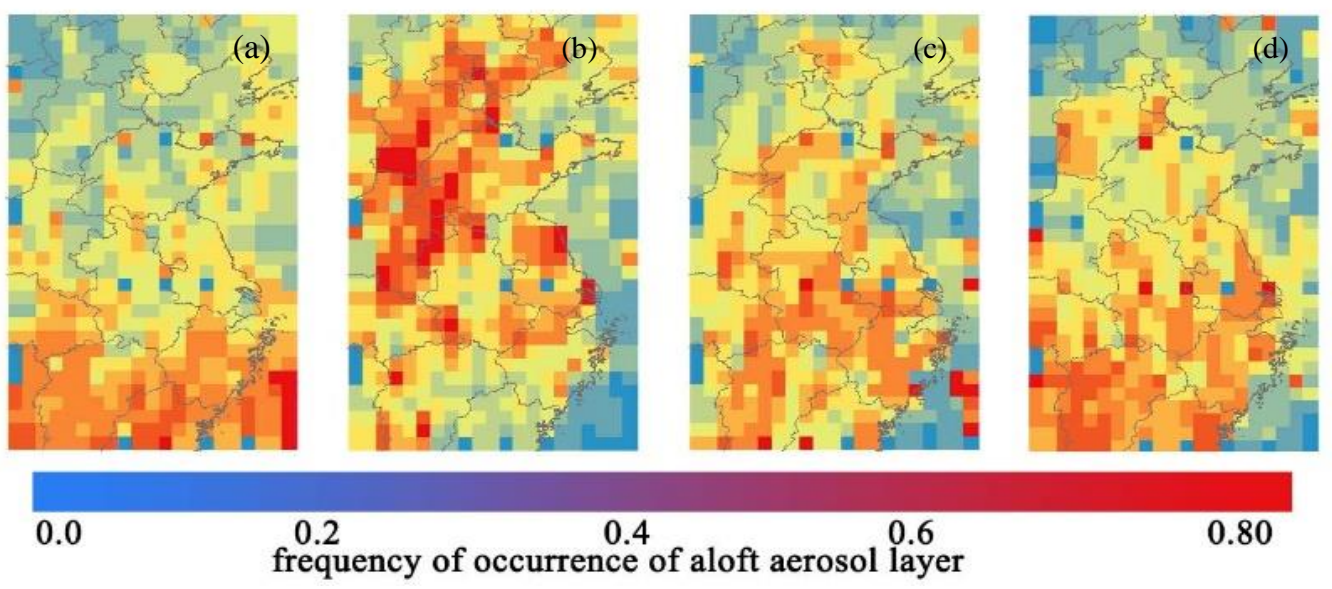

Figure 1. The spatial distribution of averaged layer top altitude of the aloft aerosol layer with a resolution of $0.25^{\circ}$ for a (spring, MAM), b (summer, JJA), c (autumn, SON) and d (winter, DJF). 

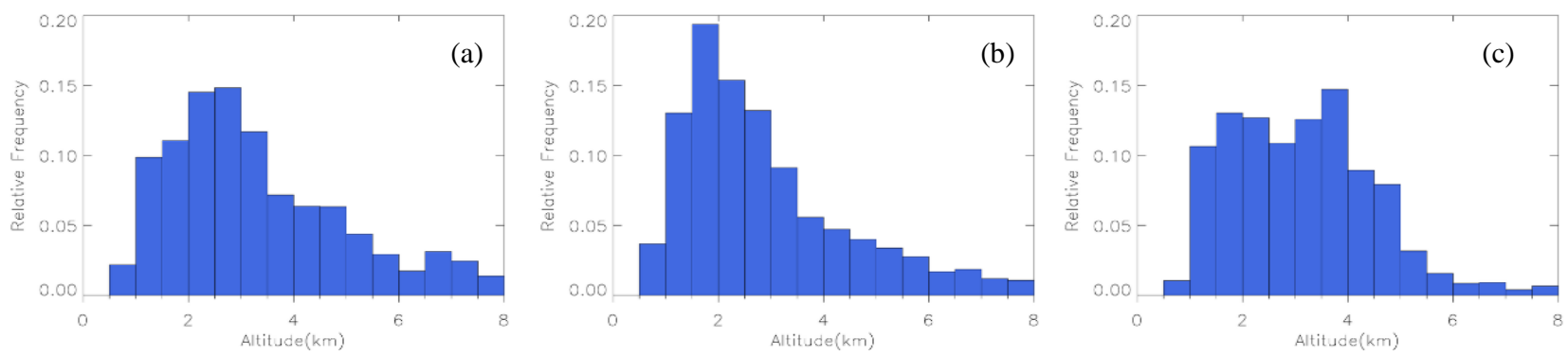

Figure 2 Histogram of layer top altitudes of aloft anthropogenic aerosols derived from CALIPSO satellite over (a) central-eastern

China, (b)NCP and (c)YRD for winters 2007-2016.

As discussed above in section 3, the Chinese anthropogenic haze layers are usually recognized as "smoke" or "polluted dust" in CALIPSO, only layers with these two subtypes were accepted here. Therefore, the variation of the two types aerosol during 10 years(2007-2016) is analyzed and the result is shown in Figure 3. In the past ten years(2007-2016) in NCP, polluted dust dominated the frequency of aloft layer compared to smoke although absolute events are likely to decrease. And from 2011 to 2016, the frequency of smoke appears to be weakening. It can still be seen that China's governance of air quality has shown initial success in recent years even people always live in the shadows of haze in the winter. But in the YRD region, the variations in the proportion of polluted dust and smoke over a decade is another situation. First of all, compared with NCP, the proportion of polluted dust in YRD is not much different from that of smoke. Secondly, in YRD area, the frequency of occurrence of aloft smoke in 2013-2016 decreased significantly which almost coincides with NCP in 2011-2016. Finally, although the proportion of smoke in YRD is higher, the absolute aloft layer events are much smaller than NCP.
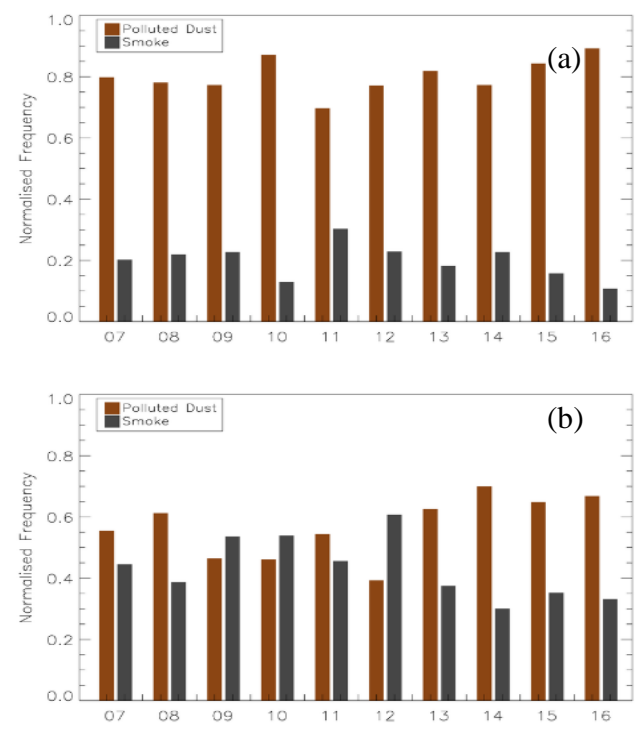

Figure 3 variations in the ratio of polluted dust and smoke over (a)NCP and (b)YRD for winter 2007-2016

The finer monthly polluted dust and smoke distributions of NCP and YRD region for winter are also analyzed as shown in Figure 4. The results show that in NCP region, polluted dust occurs about four times as often as smoke. And there is no significant variation in the proportion of three months in winter. However, different distributions are indicated in the YRD area as shown in Figure 4b. First, in December and January of the following year, the ratio of polluted dust to smoke is 6 to 4 which is a huge difference from the ratio of 4 in the NCP region. Second, in January, the proportion of smoke and polluted dust was comparable.

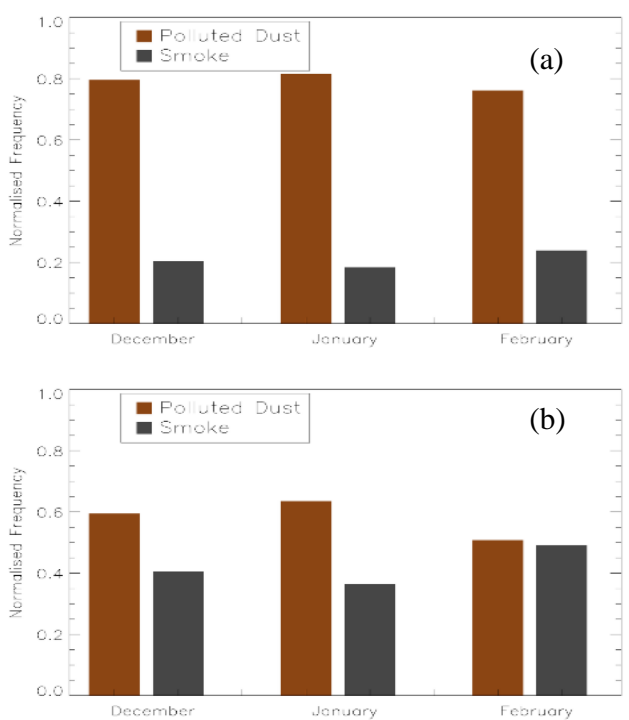

Figure 4 monthly distributions of polluted dust and smoke over (a)NCP and (b)YRD region for winter 2007-2016

In the CALIPSO algorithm scene classification algorithms, optical properties such as volume depolarization ratio and attenuated backscatter color ratio are used in conjunction with spatial information to distinguish aerosol layers from clouds. The particulate color ratio (backscatter at $1064 \mathrm{~nm} / 532 \mathrm{~nm}$ ) is an indicator of particle size and was calculated on a profile-byprofile basis and later averaged. Figure 5a shows the histogram of the particulate color ratio in eastern China for 2007-2016 winter. The particulate color ratio has a sharp peak near $0.4-0.7$ suggesting that smaller particles dominate the size distribution during the winter months. This color ratio distribution is generally consistent with the backscatter color ratios for mixed plumes (polluted dust and smoke) extracted by CALIPSO. The volume depolarization ratio is the ratio of the vertical backscattering coefficient of $532 \mathrm{~nm}$ to the parallel backscattering coefficient of $532 \mathrm{~nm}$, reflecting the degree of irregularity of the measured particulate matter. The larger the depolarization ratio is, the more irregular the particles are, and the spherical and non-spherical aerosol particles can be distinguished by the depolarization ratio. Retrieved optical 
properties of the aerosol aloft layers are shown in Figure $5 \mathrm{~b}$ with relative frequency of particulate depolarization ratio at $532 \mathrm{~nm}$, an indicator of particle shape. The volume depolarization ratio is almost distributed within 0.2 , indicating that the shape of the particles is irregular.
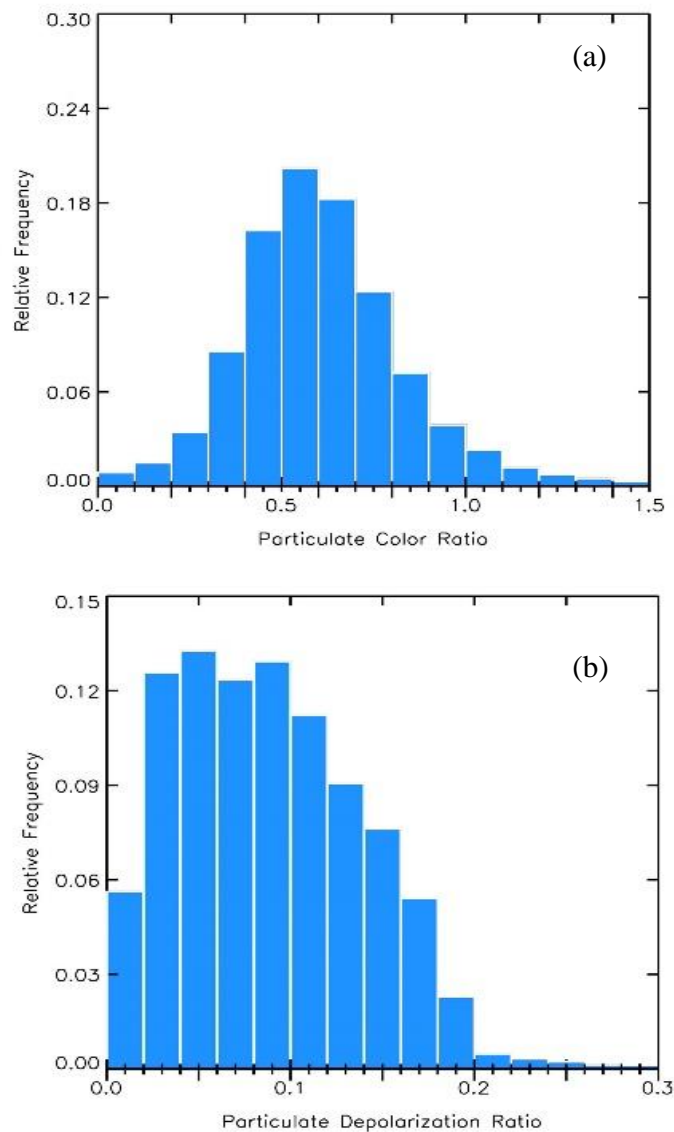

Figure 5 Histogram of (a) particulate color ratio and (b) depolarization ration derived from CALIPSO satellite over central-eastern China for winters 2007-2016.

\section{SUMMARY}

This study investigates the aloft aerosol over central-eastern China during the winter haze season, which determines the potential for long-range transport of the haze. This information is critical for aerosol transport modeling. CALIPSO observations frequently detect aloft aerosol layers in wintertime over NCP and YRD for 2007-2016. Our long-term datasets allow us to build climatology of aerosol plume transport and properties. Results shows that:

(1) The frequency of occurrence of aloft layer in South China are higher than that in North China, indicating that heat has a strong lifting effect on the PBL.

(2) The NCP has a unique high frequency value at $2.5 \mathrm{~km}$, while the YRD has two peaks, $3.5 \mathrm{~km}$ and $2 \mathrm{~km}$ respectively.

(3) In the past five years in the NCP (2011-2016) and YRD (2012-2016) regions, the anthropogenic source of pollutants dominated by smoke showed a downward trend year by year

(4) The volume depolarization ratio is almost distributed within 0.2 , indicating that the shape of the particles is irregular. The particulate color ratio has a sharp peak near $0.4-0.7$ suggesting that smaller particles dominate the size distribution during the winter months.

\section{ACKNOWLEDGEMENTS}

This study was supported by the Fundamental Research Funds for the Central Universities (2015XKMS049).

\section{REFERENCES}

Berg, L. K., Fast, J. D., Barnard, J. C., Burton, S. P., Cairns, B., Chand, D., ... \& Hair, J. W. (2016). The Two - Column Aerosol Project: Phase I-Overview and impact of elevated aerosol layers on aerosol optical depth. Journal of Geophysical Research: Atmospheres, 121(1), 336-361.

Burton, S.P., Ferrare, R.A., Vaughan, M.A., Omar, A.H., Rogers, R.R., Hostetler, C.A., \& Hair, J.A. (2013). Aerosol classification from airborne HSRL and comparisons with the CALIPSO vertical feature mask. Atmospheric Measurement Techniques, 6, $1397-1412$

Bi, J., Huang, J., Hu, Z., Holben, B. N., \& Guo, Z. (2014). Investigating the aerosol optical and radiative characteristics of heavy haze episodes in Beijing during January of 2013. Journal of Geophysical Research: Atmospheres, 119(16), 9884-9900.

Campbell, J. R., D. L. Hlavka, E. J. Welton, C. J. Flynn, D. D. Turner, J. D. Spinhirne, V. S. Scott, and I. H. Hwang, Full-time, eye-safe cloud and aerosol lidar observation at Atmospheric Radiation Measurement Program sites: Instruments and data processing, J. Atmos. Oceanic Technol.,19, 431-442, 2002.

Cottle, P., Strawbridge, K., \& McKendry, I. (2014). Long-range transport of Siberian wildfire smoke to British Columbia: Lidar observations and air quality impacts. Atmospheric Environment, 90, 71-77.

Dubovik, O., \& King, M. D. (2000). A flexible inversion algorithm for retrieval of aerosol optical properties from Sun and sky radiance measurements. Journal of Geophysical Research, 105(D16), 20673-20696.

Eck, T.F., Holben, B.N., Reid, J.S., ...\& Kinne, S. (1999). Wavelength dependence of the optical depth of biomass burning, urban, and desert dust aerosols. J. Geophys. Res., 104(3133331349).

Fernald, F. G. (1984). Analysis of atmospheric lidar observations- Some comments. Applied optics, 23(5), 652-653. Slutsker,

Flynna, C. J., Mendozaa, A., Zhengb, Y., \& Mathurb, S. (2007). Novel polarization-sensitive micropulse lidar measurement technique. Optics express, 15(6), 2785-2790.

Guo, J., Liu, H., Wang, F., Huang, J., Xia, F., Lou, M., ... \& Yung, Y. L. (2016). Three-dimensional structure of aerosol in China: A perspective from multi-satellite observations. Atmospheric Research, 178, 580-589.

Han, Y., Wu, Y., Wang, T., Zhuang, B., Li, S., \& Zhao, K. (2015). Impacts of elevated-aerosol-layer and aerosol type on the correlation of AOD and particulate matter with ground-based and satellite measurements in Nanjing, southeast China. Science of the Total Environment, 532, 195-207.

Huang, R. J., Zhang, Y., Bozzetti, C., Ho, K. F., Cao, J. J., Han, Y., ... \& Zotter, P. (2014). High secondary aerosol contribution to particulate pollution during haze events in China. Nature, 514(7521), 218-222.

Kar, J., Vaughan, M. A., Liu, Z., Omar, A. H., Trepte, C. R., Tackett, J., ... \& Kowch, R. (2015). Detection of pollution 
outflow from Mexico City using CALIPSO lidar measurements. Remote Sensing of Environment, 169, 205-211.

Li, Z., Li, C., Chen, H., Tsay, S. C., Holben, B., Huang, J., ... \& Xia, X. (2011). East Asian Studies of Tropospheric Aerosols and their Impact on Regional Climate (EAST - AIRC): An overview. Journal of Geophysical Research: Atmospheres, 116(D7).

Liu, Z., Vaughan,M.A., Winker, D.M., Kittaka, C., et al. (2009). The CALIPSO lidar cloud and aerosol discrimination: Version 2 algorithm and initial assessment of performance. Journal of Atmospheric and Oceanic Technology, 26, 1198-1213.

Mielonen, T., Arola, A., Komppula, M., Kukkonen, J., et al. (2009). Comparison of CALIOP level 2 aerosol subtypes to aerosol types derived from AERONET inversion data. Geophysical Research Letters, 36, L18804.

Niranjan, K., Madhavan, B. L., \& Sreekanth, V. (2007). Micro pulse lidar observation of high altitude aerosol layers at Visakhapatnam located on the east coast of India. Geophysical Research Letters, 34(3).

O'Neill, N. T., Eck, T. F., Smirnov, A., Holben, B. N., \& Thulasiraman, S. (2003). Spectral discrimination of coarse and fine mode optical depth. Journal of Geophysical Research: Atmospheres, 108(D17).

Omar, A. H., Winker, D. M., Vaughan, M. A., Hu, Y., Trepte, C. R., Ferrare, R. A., ... \& Kuehn, R. E. (2009). The CALIPSO automated aerosol classification and lidar ratio selection algorithm. Journal of Atmospheric and Oceanic Technology, 26(10), 1994-2014.

Qin, K., Wu, L., Wong, M. S., Letu, H., Hu, M., Lang, H., ... \& Yuan, L. (2016). Trans-boundary aerosol transport during a winter haze episode in China revealed by ground-based Lidar and CALIPSO satellite. Atmospheric Environment, 141, 20-29.

Rogers, R. R., Hair, J. W., Hostetler, C. A., Ferrare, R. A., Obland, M. D., Cook, A. L., ... \& Clarke, A. D. (2009). NASA LaRC airborne high spectral resolution lidar aerosol measurements during MILAGRO: observations and validation. Atmospheric Chemistry and Physics, 9(14), 4811-4826.

Salinas, S. V., Chew, B. N., Miettinen, J., Campbell, J. R., Welton, E. J., Reid, J. S., ... \& Liew, S. C. (2013). Physical and optical characteristics of the October 2010 haze event over Singapore: A photometric and lidar analysis. Atmospheric Research, 122, 555-570.

Sarangi, C., Tripathi, S. N., Mishra, A. K., Goel, A., \& Welton, E. J. (2016). Elevated aerosol layers and their radiative impact over Kanpur during monsoon onset period. Journal of Geophysical Research: Atmospheres,121(13), 7936-7957.

Strong, S. B., \& Brown, A. M. (2014, June). Developing a broad spectrum atmospheric aerosol characterization for remote sensing platforms over desert regions. In SPIE Defense+ Security (pp. 907115-907115). International Society for Optics and Photonics.

Sun, Y., Chen, C., Zhang, Y., Xu, W., Zhou, L., Cheng, X., ... \& Fu, P. (2016). Rapid formation and evolution of an extreme haze episode in Northern China during winter 2015. Scientific reports, 6, 27151.

Sun, Y., Jiang, Q., Wang, Z., Fu, P., Li, J., Yang, T., \& Yin, Y. (2014). Investigation of the sources and evolution processes of severe haze pollution in Beijing in January 2013. Journal of Geophysical Research: Atmospheres, 119(7), 4380-4398.
Tao, M., Chen, L., Xiong, X., Zhang, M., Ma, P., Tao, J., \& Wang, Z. (2014). Formation process of the widespread extreme haze pollution over northern China in January 2013: Implications for regional air quality and climate. Atmospheric Environment, 98, 417-425.

Tao, M., Chen, L., Wang, Z., Wang, J., Tao, J., \& Wang, X. (2016). Did the widespread haze pollution over China increase during the last decade? A satellite view from space. Environmental Research Letters, 11(5), 054019.

Winker, D. M., Hunt, W. H., \& McGill, M. J. (2007). Initial performance assessment of CALIOP. Geophysical Research Letters, 34(19).

Winker, D. M., Vaughan, M. A., Omar, A., Hu, Y., Powell, K. A., Liu, Z., ... \& Young, S. A. (2009). Overview of the CALIPSO mission and CALIOP data processing algorithms. Journal of Atmospheric and Oceanic Technology,26(11), 2310-2323.

Wu, Y., Cordero, L., Gross, B., Moshary, F., \& Ahmed, S. (2012). Smoke plume optical properties and transport observed by a multi-wavelength lidar, sunphotometer and satellite. Atmospheric environment, 63, 32-42.

Wu, Y., Cordero, L., Gross, B., Moshary, F., \& Ahmed, S. (2014). Assessment of CALIPSO attenuated backscatter and aerosol retrievals with a combined ground-based multi-wavelength lidar and sunphotometer measurement. Atmospheric environment, 84 , 44-53.

Wu, Y., Nazmi, C., Han, Z., Li, C., Gross, B., \& Moshary, F. (2016). Integrated Observation of Aerosol Plumes Transport and Impacts on the Air Quality Remote Sensing in the Northeast US. In EPJ Web of Conferences (Vol. 119, p. 18004). EDP Sciences.

Welton, E. J., Voss, K. J., Gordon, H. R., Maring, H., Smirnov, A., Holben, B., ... \& Formenti, P. (2000). Ground - based lidar measurements of aerosols during ACE - 2: Instrument description, results, and comparisons with other ground - based and airborne measurements. Tellus B, 52(2), 636-651.

Welton, E. J., Voss, K. J., Quinn, P. K., Flatau, P. J., Markowicz, K., Campbell, J. R., ... \& Johnson, J. E. (2002). Measurements of aerosol vertical profiles and optical properties during INDOEX 1999 using micropulse lidars. Journal of Geophysical Research: Atmospheres, 107(D19).

Yang, T., Wang, X., Wang, Z., Sun, Y., Zhang, W., Zhang, B., \& Du, Y. (2012). Gravity-current driven transport of haze from North China Plain to Northeast China in winter 2010-Part I: observations. Sola, 8(0), 13-16.

Zhang, X., Wang, L., Wang, W., Cao, D., Wang, X., \& Ye, D. (2015). Long-term trend and spatiotemporal variations of haze over China by satellite observations from 1979 to 2013. Atmospheric Environment, 119, 362-373.

Zheng, G. J., Duan, F. K., Su, H., Ma, Y. L., Cheng, Y., Zheng, B., ... \& Pöschl, U. (2015). Exploring the severe winter haze in Beijing: the impact of synoptic weather, regional transport and heterogeneous reactions.Atmospheric Chemistry and Physics, 15(6), 2969-2983. 